\title{
Prevalence of Campylobacter jejuni in chicken produced by major poultry companies in Saudi Arabia
}

Hany M Yehia ${ }^{1,2^{*}}$ and Mosffer M AL-Dagal ${ }^{1 *}$

\begin{abstract}
Background: Campylobacter is a foodborne pathogen that is commonly associated with chicken. The aim of this work was to evaluate the prevalence of Campylobacter jejuni (as affected by refrigerated storage) in chicken samples obtained from the wholesale poultry market in the northern part of Riyadh City, Saudi Arabia.

Findings: A gradual increase in the number of positive samples was noted during storage at $4^{\circ} \mathrm{C}$. On days 1,3 , and 7 , the number of positive samples were 10 (30.305\%), 15 (45.45\%), and 27 (81.81\%), respectively. Of 99 tested samples, 52 (52.25\%) were positive for Campylobacter jejuni. Protein profiling by Sodium dodecyl sulfate -Polyacrylamide gel electrophoresis (SDS-PAGE) was used to identify Campylobacter jejuni. The results were verified using Analytical Profile Index (API Campy system, Marcy l'Etoile, France). Forty-three (82.69\%) positive isolates were identified as C. jejuni subsp. jejuni 2, 5 isolates as C. jejuni subsp. jejuni 1 (9.61\%), and 4 isolates as C. jejuni subsp. doylei (7.69).
\end{abstract}

Conclusion: C. jejuni positive samples increased rapidly during storage at $4^{\circ} \mathrm{C}$ for approximately 1 wk. Our results also indicated a connection between the protein profiles on SDS-PAGE and API Campy used for the identification of C. jejuni.

Keywords: Campylobacter jejuni; Chicken; Refrigeration storage

\section{Introduction}

Campylobacter jejuni is a well-known food-borne pathogen, transmitted to humans by the eating of warm-blooded animal meat, especially poultry (Jay et al. 2005; Nielsen et al. 1997). This bacterium is a major cause of food-borne diarrhea in many countries (Crushell et al. 2004; Iovine et al. 2008. It has gained more attention in the last 30 years because it has been recognized as a major cause of human illnesses, ranging from gastroenteritis to Guillain-Barré Syndrome (Khanna et al. 1996; Tauxe, 2001; Moore et al. 2005). The 2 most frequently occurring Campylobacter species that are of clinical significance because of meat consumption and meat products are C. jejuni and C. coli. Campylobacter jejuni accounts for more than $90 \%$ of incidences of human campylobacteriosis (Lindmark et al. 2009). Campylobacteriosis in humans results from eating undercooked meat and/or contaminated meals (Corry and

\footnotetext{
* Correspondence: hanyyehia43@yahoo.de; maldagal@ksu.edu.sa

'Food Science and Nutrition Department, College of Food and Agricultural

Sciences, King Saud University, Riyadh, Saudi Arabia

Full list of author information is available at the end of the article
}

Atabay 2001). Survey studies have revealed a high prevalence of Campylobacter in poultry meats (Dickins et al. 2002; Ridsdale et al. 1998; Stoyanchev et al. 2007).

Few studies on Campylobacter in the Saudi Arabian food market have been performed. Therefore, this study investigates the prevalence of Campylobacter jejuni in locally produced refrigerated chicken carcasses, as affected by storage time. Whole-cell protein profiles of presumptive Campylobacter isolates were compared with the standard strain of Campylobacter jejuni ATCC 33291 on SDS page. High degree of similarity within standard strain was confirmed by biochemical identification using an API CAMPY biotyping identification system.

\section{Materials and methods \\ Sample collection}

Whole chicken carcasses $(n=99)$ were obtained from a wholesale poultry market located in the northern part of Riyadh City, Saudi Arabia. The samples were collected from 11 major national poultry companies (designated by the letters A through K). Nine samples were collected from each company. The samples were transported at

\section{Springer}


refrigeration temperature to the Food Microbiology Laboratory, College of Food and Agricultural Sciences, King Saud University.

\section{Experimental design}

Refrigerated chicken samples were divided into 3 groups. The first group (including 33 samples, 3 samples (3 runs) per company) was tested for the presence of Campylobacter jejuni on Day 1 (the purchase date). Similarly, the next 2 groups (33 samples each) were tested for the microorganism at Day 3 and Day 7 after the purchase date and stored in refrigerator at $4^{\circ} \mathrm{C}$.

\section{Isolation and identification of Campylobacter}

Campylobacter jejuni was isolated according to the methods described by the Food Safety and Inspection Service (FSIS) (1998). Each carcass was rinsed in a sterile plastic bag with the addition of $200 \mathrm{~mL}$ of $0.1 \%$ peptone by manual shaking for $60 \mathrm{~s}$. Ten milliliters of the rinse was centrifuged at $5000 \mathrm{rpm}$ for $5 \mathrm{~min}$, and 2 loops of the pellet were streaked on modified charcoal cefoperazone deoxycholate agar (mCCDA, Oxoid CM739, Basingstoke, Hampshire, UK) and Campylobacter-selective agar (Preston, Oxoid CM0689). Preston Campylobacter selective supplement (Oxoid, SR0117) and lysed horse blood (Oxoid, SR0048) were used for the selective isolation of Campylobacter jejuni from the samples (Figueroa et al. 2009). As a confirmation step, $10 \mathrm{~mL}$ of each rinse fluid was transferred to $90 \mathrm{~mL}$ of Preston enrichment broth (to prepare Preston Campylobacter selective enrichment broth, $12.5 \mathrm{~g}$ of Nutrient Broth No.2 (Oxoid CM0067) was dissolved in $475 \mathrm{ml}$ of distilled water and sterilized by autoclaving at $121^{\circ} \mathrm{C}$ for 15 minutes. Twenty five $25 \mathrm{ml}$ of Lysed Horse Blood (Oxoid SR0048), 1 vial of Preston Campylobacter Selective Supplement (Oxoid SR0117) and 1 vial of Campylobacter Growth Supplement (Oxoid, SR0232) were added to the cooled $475 \mathrm{ml}$ medium. Five $\mathrm{ml}$ volumes were aseptically dispensed in sterile small screw-capped bottles and incubated at $37^{\circ} \mathrm{C}$ for $48 \mathrm{~h}$ in a gas mixture of BBL GasPak, 70304 (Becton Dickinson and Cockeysville, $\mathrm{MD}$, USA), (5\% $\mathrm{O}_{2}, 10 \% \mathrm{CO}_{2}$, and $85 \% \mathrm{~N}_{2}$ ). The enrichment was streaked onto selective media, and the plates were incubated at $42^{\circ} \mathrm{C}$ for up to $48 \mathrm{~h}$ under microaerophilic conditions. After incubation, the plates were inspected for presumptive colonies before Gram staining, and cells resembling with Campylobacter were subcultured onto mCCDA by streaking colony method and incubated for 2 to $5 \mathrm{~d}$ at $42^{\circ} \mathrm{C}$ under microaerophilic conditions.

\section{Polyacrylamide Gel Electrophoresis (PAGE)}

The preparation of isolates for SDS-PAGE and the running of the samples were performed according to the method by Scarcelli et al. 2001. Electrophoresis was performed in a
$12 \%$ polyacrylamide running gel and a $4 \%$ stacking gel, with a $0.025 \mathrm{M}$ Tris $0.19 \mathrm{M}$ glycine buffer $\mathrm{pH} 8.3$, and $100 \mu \mathrm{L}$ of a sucrose buffer (50 mM Tris- $\mathrm{HCl}, \mathrm{pH} 8 ; 40$ mM EDTA, $\mathrm{pH} 8 ; 0.75 \mathrm{M}$ sucrose).

\section{Preparation of cell extract}

An overnight culture $(100 \mu \mathrm{L})$ was inoculated into a $10 \mathrm{ml}$ of fresh medium (Brain heart infusion-Oxoid, CM1135) and grown to an Optical Density (OD) 620 of 0.6 to 0.8 (3 to $4 \mathrm{~h}$ ). The cells were collected and weighed, and $250 \mathrm{mg}$ of cells were then suspended in $100 \mu \mathrm{L}$ of a TES buffer (50 mM tris $\mathrm{HCl}, \mathrm{pH} 8,1 \mathrm{mM}$ EDTA, 25\% sucrose). Twenty microliters of lysozyme $(50 \mathrm{mg} / \mathrm{mL})$ and $5 \mu \mathrm{L}$ mutanolysin $(5000 \mathrm{u} / \mathrm{mL})$ were added to the suspended cells in the TES buffer and incubated at $37^{\circ} \mathrm{C}$ for $30 \mathrm{~min}$. Five to ten microliters of $20 \%$ SDS were added, and the contents were mixed until they became clear visible. The contents were stored at $-20^{\circ} \mathrm{C}$ for 1 to $2 \mathrm{~d}$ (Ismail 2007).

Fifty-microliter extracts (standard and isolated bacteria) were loaded on SDS-PAGE. Electrophoresis was performed at $25^{\circ} \mathrm{C}$ in a vertical tank apparatus using a constantvoltage power supply, until a bromophenol blue tracking dye reached the bottom of the gel. Gels were stained with 0.25\% Coomassie Brilliant Blue R-250 (Bio-Rad, Marnesla-Coquette, France) in water: methanol: acetic acid (6.5:2.5:1) for $18 \mathrm{~h}$ at room temperature. Gel destaining was performed by continuous agitation in a methanol: acetic acid: water $(20: 10: 70 \mathrm{v} / \mathrm{v} / \mathrm{v})$ solvent until obvious bands of proteins were obtained.

Whole-cell protein profiles of presumptive Campylobacter isolates were compared with the standard strain of Campylobacter jejuni ATCC 33291 on SDS-PAGE. A high degree of similarity with the standard strains was confirmed by biochemical identification using an API CAMPY biotyping system and a catalase test.

\section{Biochemical identification of Campylobacter isolates}

BioMérieux API CAMPY was used according to the manufacturer's instructions for the biochemical identification of Campylobacter. The BioMérieux API CAMPY strip consisted of 20 microtubes containing dehydrated substances, with each microtubule corresponding to an individual test. The 20 tests were divided into 2 parts; the first part was composed of enzymatic and conventional tests, and the second part comprised assimilation or inhibition tests (Gorman and Adley 2005). The results of the enzymatic tests were obtained with the addition of conventional reagents after $24 \mathrm{~h}$ of incubation at $37^{\circ} \mathrm{C}$ under aerobic conditions. The results of the assimilation and inhibition tests were recorded after $24 \mathrm{~h}$ at $37^{\circ} \mathrm{C}$ under microaerophilic conditions. Incubation was extended to $48 \mathrm{~h}$ if the succinate assimilation test was negative, as indicated by the manufacturer's instructions. 


\section{Results and discussion}

Table 1 shows the prevalence of $C$. jejuni in refrigerated chicken samples, as affected by storage time. According to the table, the samples from all 11 poultry companies contained $C$. jejuni at one or more of the tested shelf-life dates. At Day 1 of the shelf life, C. jejuni was recovered from $30.30 \%$ of the tested samples (10 of 33 samples). This percentage increased to $44.45 \%$ and to $81.81 \%$, after refrigeration for $3 \mathrm{~d}$ and $7 \mathrm{~d}$, respectively, indicating the positive effect of natural enrichment. Poultry companies B, C, I, and $\mathrm{J}$ had included highly positive samples for $C$. jejuni $(\mathrm{n}=6$; 66.7\%), followed by $A$ and $E(n=5 ; 55.6 \%)$, and then $D, F$, and $K(n=4 ; 44.4 \%)$. Only one sample $(n=1 ; 11.1 \%)$, from company $\mathrm{G}$, was positive.

Survival of $C$. jejuni at refrigeration temperature approved in one study. The outcome of this work agreed with other research works indicating that the survival of $C$. jejuni at refrigeration temperature range $\left(4\right.$ to $\left.7^{\circ} \mathrm{C}\right)$ is better than range $\left(20\right.$ to $\left.30^{\circ} \mathrm{C}\right)$, and that it exhibits greater survivability at chilled temperatures (Karenlampi and Hanninen 2004; El-Shibiny et al. 2009). Rollins and Colwell (1986) showed that, at $4^{\circ} \mathrm{C}, \mathrm{C}$. jejuni can survive and remain at a viable but non-culturable stage for approximately $4 \mathrm{mo}$. Zhao et al. (2000) showed that C. jejuni survive for days or weeks in refrigerated foodstuffs. Vashin and Stoyanchev (2011) established that the microorganisms did not grow in chilled or frozen meat, but are able to survive during the storage period at $1-4^{\circ} \mathrm{C}$. Campylobacter were detected up to the $25^{\text {th }}$ days while at -18 to $-20^{\circ} \mathrm{C}$ : up to the $45^{\text {th }}$ day. The juice released into the bags from poultry liquidation is highly nutritive and forms microaerophilic conditions suitable for Campylobacter. Birk et al. (2004) confirmed that compounds present in chicken juice protect, and thus, prolong the survival of $C$. jejuni during storage at refrigerator temperatures. They confirmed that incubation at $5^{\circ} \mathrm{C}$ extended viability of cells of $C$. jejuni, and incubation at $10^{\circ} \mathrm{C}$ significantly prolonged the viability of Campylobacter. In addition, they found that storage in chicken juice at both $5^{\circ} \mathrm{C}$ and $10^{\circ} \mathrm{C}$ significantly prolonged the viable cells of $C$. jejuni compared to incubation in reference media. The total number of samples tested positive for C. jejuni was 52 (52.52\%). Similar results in a previous survey study (Rahimi and Tajbakhsh 2008) found $56.1 \%$ of chicken samples to be positive for Campylobacter. Few studies related to the occurrence of Campylobacter in Saudi Arabian food market, from 2002 to 2004, two studies were conducted to assess specimens obtained from slaughter-houses in Bahrain and Saudi Arabia for Campylobacter contamination. In one study, specimens consisting of 35 whole chickens, 27 chicken livers, and 38 chicken faeces were assessed using a combination of three culture methods, and just over half (57\%) were found to be positive for Campylobacter contamination (Ghazwan 2006). In another study, 60 chicken faeces specimens were assessed using a newly developed multiplex PCR technique with 100\% Campylobacter detection (Al Amri et al. 2007). However, in both studies, C. jejuni accounted for the majority of Campylobacter detected. The findings of this study, which is the first of its kind in our setting, indicates a need for

Table 1 Prevalence of Campylobacter jejuni in refrigerated whole chicken carcasses of 11 poultry companies in Riyadh City wholesale market

\begin{tabular}{|c|c|c|c|c|c|c|c|c|c|c|c|}
\hline \multirow[t]{2}{*}{ Poultry samples } & \multicolumn{3}{|c|}{$\begin{array}{l}\text { Group } 1 \\
\text { First day of the } \\
\text { production date }\end{array}$} & \multicolumn{3}{|c|}{$\begin{array}{l}\text { Group } 2 \\
3^{\text {rd }} \text { days of the } \\
\text { production date }\end{array}$} & \multicolumn{3}{|c|}{$\begin{array}{l}\text { Group } 3 \\
7^{\text {th }} \text { day of the } \\
\text { production date }\end{array}$} & \multirow{2}{*}{$\begin{array}{l}\text { Total } \\
\text { Positive } \\
\text { (out of 9) }\end{array}$} & \multirow[t]{2}{*}{$\%$} \\
\hline & Run1 & Run2 & Run3 & Run1 & Run2 & Run3 & Run1 & Run2 & Run3 & & \\
\hline A & + & - & - & + & - & - & + & + & + & 5 & 55.6 \\
\hline B & - & - & + & + & - & + & + & + & + & 6 & 66.7 \\
\hline C & - & + & - & + & + & + & + & + & - & 6 & 66.7 \\
\hline D & - & + & - & - & - & - & + & + & + & 4 & 44.4 \\
\hline E & + & - & - & + & - & + & - & + & + & 5 & 55.6 \\
\hline $\mathbf{F}$ & - & - & + & + & - & + & - & + & - & 4 & 44.4 \\
\hline G & - & - & - & - & - & - & - & + & - & 1 & 11.1 \\
\hline H & + & - & - & + & - & - & + & + & + & 5 & 55.6 \\
\hline I & - & + & - & + & - & + & + & + & + & 6 & 66.7 \\
\hline J & - & - & + & + & & + & + & + & + & 6 & 66.7 \\
\hline K & - & + & - & - & - & - & + & + & + & 4 & 44.4 \\
\hline Number of total samples & 33 & & & 33 & & & 33 & & & 99 & \\
\hline Number of positive sample & 10 & & & 15 & & & 27 & & & 52 & - \\
\hline$\%$ & 30.30 & & & 45.45 & & & 81.81 & & & 52.52 & - \\
\hline
\end{tabular}




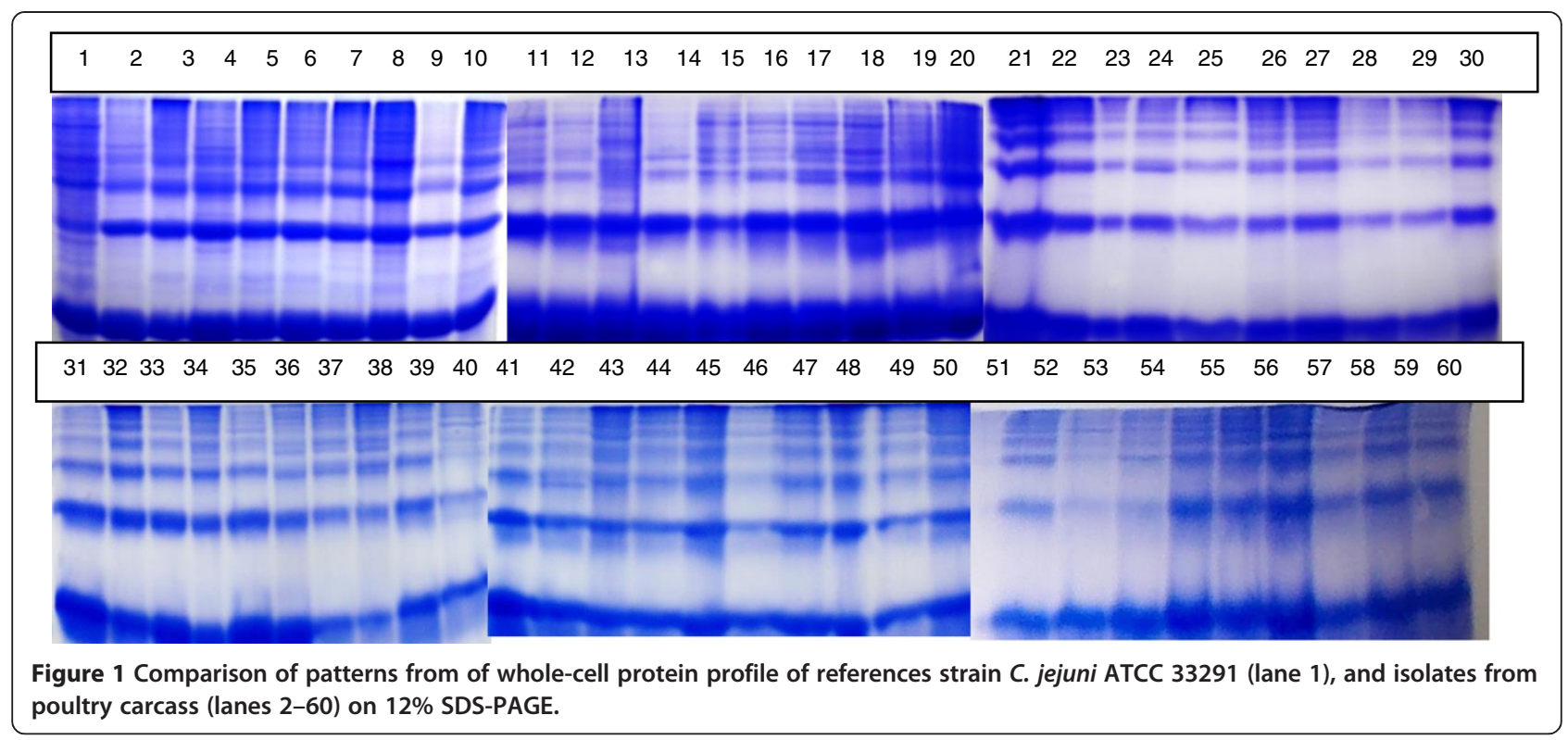

increased surveillance and Campylobacter screening in food safety control to better protect consumers.

Figure 1 shows the protein profiles of the isolates as they appeared on the media of mCCDA and Preston agar compared with standard strains of $C$. jejuni ATCC 33291 on SDS-PAGE. The results demonstrated the presence of the common heavy protein band for 52 isolates compared with $C$. jejuni ATCC 33291. The wholecell protein profiles of isolates were closely related to $C$. jejuni ATCC 33291. Some isolates could not be analyzed because they did not yield sufficient proteins after extraction, or the band did not resemble C. jejuni ATCC 33291. Any isolates showing discrepancy with the protein profile were excluded from confirmation of identification by using API CAMPY. Massai et al. (2007) explained that the whole-cell protein profile determined by SDS-PAGE expresses an important proportion of the genome. However, this expression may be modified by various factors. Therefore, this technique must be carefully controlled and standardized to obtain reproducible results. Advantages of the SDS-PAGE patterns are that they can be obtained in a short time, are reproducible, and do not require any sophisticated and expensive reagents or equipment compared with other molecular biology.

The polyacrylamide gel electrophoresis (PAGE) of bacterial proteins is an efficient technique for the classification of microorganisms, based on phenotypical characteristics expressed by their protein profiles (Scarcelli et al. 2001). Protein electrophoretic analysis of Campylobacter spp. in a polyacrylamide gel in the presence of SDS supplies data that can be used in epidemiological and taxonomic studies, as well as the identification of species and specific virulence factors (Dunn et al. 1987).

\section{API campy strip system}

After 24 to $48 \mathrm{~h}$ of incubation, the positive isolates obtained from SDS-PAGE were confirmed using API Campy, with 52 of 99 samples (52.52\%) testing positive for both the first part and second part of the tests. Eleven of 99 (11.11\%) isolates were negative. Forty-three of the 52 (82.69\%) positive isolates were identified in both parts of the tests as $C$. jejuni subsp. jejuni 2. Five isolates were identified as C. jejuni subsp. jejuni 1 (9.61\%), and 4 isolates were identified as Campylobacter jejuni subsp. doylei (7.96\%). The reference strains were correctly identified by both systems as C. jejuni ssp. jejuni 1. Eleven isolates yielded discrepant identifications, and yielded profile codes absent in the API Campy database; therefore, they were considered negative results. Huysmans and Turnidge (1997) indicated that the correlation between API Campy and the conventional tests was $100 \%$ for the identification of $C$. jejuni.

\section{Conclusion}

The results show that Campylobacter jejuni was prevalent in poultry meat samples collected from wholesale markets in Riyadh City, Saudi Arabia. C. jejuni positive samples increased rapidly during storage at $4^{\circ} \mathrm{C}$ for approximately $1 \mathrm{wk}$. Our results also indicated a connection between the protein profiles on SDS-PAGE and API Campy used for the identification of $C$. jejuni.

\section{Competing interests}

The authors declare that they have no competing interests.

\section{Authors' contributions}

Conceived and designed the experiments: YHM and AMM. Performed the experiments: YHM . Analyzed the data: YHM and AMM. Wrote the manuscript: YHM and AMM. All authors read and approve the final manuscript. 


\section{Author details}

${ }^{1}$ Food Science and Nutrition Department, College of Food and Agricultural Sciences, King Saud University, Riyadh, Saudi Arabia. ${ }^{2}$ Food Science and Nutrition Department, Faculty of Home Economics, Helwan University, Cairo, Egypt.

Received: 26 January 2014 Accepted: 7 April 2014

Published online: 29 July 2014

\section{References}

Al Amri A, Senok AC, Ismaeel AY, Al-Mahmeed AE, Botta GA (2007) Multiplex PCR for direct identification of Campylobacter spp. in human and chicken stools. Jed Microbiol 56:1350-1355

Birk T, Ingmer H, Andersen MT, Jorgensen K, Brondsted L (2004) Chicken juice, a food-based model system suitable to study survival of Campylobacter jejuni. Lett Appl Microbiol 38:66-71

Corry JE, Atabay HI (2001) Poultry as a source of Campylobacter and related organisms. Symp Ser Soc Appl Microbiol 30:96S-114S

Crushell E, Harty S, Sharif F, Bourke B (2004) Enteric Campylobacter: purging its secrets? Pediatr Res 55:3-12

Dickins MA, Franklin S, Stefanova R, Schutze GE, Eisenach KD, Wesley I, Cave MD (2002) Diversity of Campylobacter isolates from retail poultry carcasses and from humans as demonstrated by pulsed-field gel electrophoresis. J Food Prot 65:957-962

Dunn BE, Blaser MJ, Snyder EL (1987) Two dimensional gel electrophoresis and immunoblotting of Campylobacter outer membrane proteins. Infect Immun 55:1564-1572

El-Shibiny A, Scott A, Timms A, Metawea Y, Connerton P, Connerton I (2009) Application of a group II Campylobacter bacteriophage to reduce strains of Campylobacter jejuni and Campylobacter coli colonizing broiler chickens. J Food Prot 72:733-740

Figueroa G, Troncoso M, Lopez C, Rivas P, Toro M (2009) Occurrence and enumeration of Campylobacter spp. during the processing of Chilean broilers. BMC Microbiol 9:94

Food Safety and Inspection Service (FSIS) (1998) Isolation, Identification and Enumeration of Campylobacter jejuni/coli from meat and poultry products. Microbiology Laboratory Guidebook. Chapter 3rd edition, United States Department of Agriculture, Washington D.C.

Ghazwan J (2006) Public Health Importance of Campylobacter jejuni in Poultry [dissertation]. Arabian Gulf University, Manama, Bahrain, p 66

Gorman R, Adley CC (2005) Campylobacter Isolation, Identification, and Preservation .From: Methods in Biotechnology, Vol. 21. In: Adley CC (ed) Food Borne Pathogens: Methods and Protocols. @ Humana Press Inc, Totowa, NJ

Huysmans MB, Turnidge JD (1997) Disc susceptibility testing for thermophilic Campylobacters. Pathology 29:209-216

lovine NM, Pursnani S, Voldman A, Wasserman G, Blaser MJ, Weinrauch Y (2008) Reactive nitrogen species contribute to innate host defense against Campylobacter jejuni. Infect Immun 76:986-993

Ismail EA (2007) Ph. Thesis Characterization and Genetic Improvement of Lactobacillus for Application in Probiotics Dairy Probiotic Dairy Products. University of Kiel, Germany

Jay J, Loessner M, Golden DA (2005) Modern Food Microbiology, 7th edition. Springer, New York

Karenlampi R, Hanninen ML (2004) Survival of Campylobacter jejuni on various fresh produce. Int J Food Microbiol 97:187-195

Khanna PN, Kumar A, Singh AK, Khan IA (1996) Thermophilic Campylobacters public health importance and our observations. Indian J Comp Microbiol Immunol Infect Dis 17:32-40

Lindmark H, Boqvist S, Ljungstrom M, Agren P, Bjorkholm B, Engstrand L (2009) Risk factors for Campylobacteriosis: an epidemiological surveillance study of patients and retail poultry. J Clin Microbiol 47(8):2616-2619

Massai R, Bantarc C, Lopardo H, Vay C, Gutkind G (2007) Whole-cell protein profiles are useful for distinguishing enterococcal species recovered from clinical specimens. Rev Argent Microbiol 39:199-203

Moore JE, Corcoran D, Dooley JSG, Fanning S, Lucey B, Matsuda M, McDowell R, O'Riordan L, O'Rourke M, Rao JR, Rooney PJ, Sails A, Whyte P (2005) Campylobacter. Vet Res 36:351-382

Nielsen EM, Engberg J, Madsen M (1997) Distribution of serotypes of Campylobacter jejuni and C. coli from Danish patients, poultry, cattle and swine. FEMS Immunol Med Microbiol 19:47-56
Rahimi E, Tajbakhsh E (2008) Prevalence of Campylobacter species in poultry meat in the Esfahan city, Iran. Bulg J Vet Med 11:257-262

Ridsdale JA, Atabay HI, Corry JEL (1998) Prevalence of Campylobacters and Arcobacters in ducks at the abattoir. J Appl Microbiol 85:567-573

Rollins DM, Colwell RR (1986) Viable but non culturable stage of Campylobacter jejuni and its role in survival in the natural aquatic environment. Appl Environ Microbiol 52:531-538

Scarcelli E, Elizabeth OC, Margareth EG, Maristela VC, Erna EB, Ana PT (2001) Comparison of electrophoretic protein profiles of Campylobacter jejuni subsp. Jejuni isolated from different animal species. Braz J Microbiol 32(4):286-292

Stoyanchev T, Vashin I, Ring C, Atanassova V (2007) Prevalence of Campylobacter spp. in poultry and poultry products for sale on the Bulgarian retail market. Anton Leeuw 92:285-288

Tauxe RV (2001) Incidence, Trends and Sources of Campylobacteriosis in Developed Countries: An Overview. In the Increasing Incidence of Human Campylobacteriosis. Report and Proceedings of a WHO Constitution of Experts Copenhagen, Denmark, 21-25 November 2000, pp. 42-43. World Health Organization, Geneva

Vashin IT, Stoyanchev TT (2011) Influence of temperature on Campylobacter jejuni survival rates in pork meat. Bulg J Vet Med 14(1):25-30

Zhao T, Doyle MP, Berg DE (2000) Fate of Campylobacter jejuni in butter. J Food Prot 63:120-122

doi:10.1186/s40550-014-0002-y

Cite this article as: Yehia and AL-Dagal: Prevalence of Campylobacter jejuni in chicken produced by major poultry companies in Saudi Arabia. International Journal of Food Contamination 2014 1:2.

\section{Submit your manuscript to a SpringerOpen ${ }^{\odot}$ journal and benefit from:}

- Convenient online submission

- Rigorous peer review

- Immediate publication on acceptance

- Open access: articles freely available online

- High visibility within the field

- Retaining the copyright to your article

Submit your next manuscript at $>$ springeropen.com 